$$
\min _{\alpha} \frac{1}{2} \sum_{y \in Y} \sum_{i} \sum_{j} \alpha_{i}^{y} \alpha_{j}^{y}\left\langle x_{i}, x_{j}\right\rangle+\sum_{y \in Y} \sum_{i}\left(1-\delta y_{i}, y\right) \alpha_{i}^{y}
$$

при неотрицательных коэффициентах

Преимущества мультиклассового метода опорных векторов:

- автоматически определяется чиејф нейронов скрытого слоя. Оно равно числу опорных векторов.

- принцип оптимальной разделяющей гиперплоскости приводит к максимизации ширины разделяющей полосы между классами, следовательно, к более уверенной классификации. Градиентные нейросетевые методы выбирают положение разделяющей гиперплоскости произвольным образом.

- Недостатки мультиклассового метода опорных векторов:

- метод опорных векторов неустойчив по отношению к шуму в исходных данных. Если обучающая выборка содержат шумовые выбросы, они будут существенным образом учтены при построении разделяющей гиперплоскости. Этого недостатка лишён метод релевантных векторов (relevance vector machine, RVM). В отличие от SVM данный метод дает вероятности, с которыми объект принадлежит данному классу. Т.е. если SVM говорит «х принадлежит классу A», то RVM скажет «х принадлежит классу А с вероятностью р и классу В с вероятностью 1-р».

- в общем случае, когда линейная разделимость не гарантируется, приходится подбирать управляющий параметр алгоритма [2].

$$
* * *
$$

1. Акинин М.В., Конкин Ю.В. Особенности обучения машины опорных векторов в задачах формирования карт лесов // Методы и средства обработки и хранения информации. 2010, - С. 130-140.

2. Bartlett P., Shawe-Taylor J. Generalization performance of support vector machines and other pattern classifiers // Advances in Kernel Methods. - MIT Press, Cambridge, USA, 1998.

\title{
Воробьев А.И. ${ }^{1}$, Колбанёв М.О. ${ }^{2}$ Инфокоммуникация и архитектура цифровой экономики \\ ${ }^{1}$ Санкт-Петербургский государственный электротехнический университет «ЛЭТИ» им. В.И. Ульянова (Ленина) \\ ${ }^{2}$ Санкт-Петербургский государственный экономический университет \\ (Россия, Санкт-Петербург)
} doi: $10.18411 / s r-10-12-2017-03$ idsp: 000001:sr-10-12-2017-03

\section{Аннотация}

В статье рассмотрены особенности архитектурных подходов к созданию централизованных и децентрализованных цифровых платформ на базе инфокоммуникационных сетей и систем. Многоцелевая модель перехода к цифровой экономике, цифровые платформы и экосистема цифровой экономики. Рассмотрены децентрализованные цифровые платформы блокчейн и связанные с ним понятия, программируемая экономика, иерархия технологий, примеры приложений.

Ключевые слова: инфокоммуникация, цифровая экономика, программируемая экономика, цифровая платформа, блокчейн, майнинг.

Для создания цифровой экономики нужно достигнуть 3-х взаимосвязанных целей[1]. На глобальном уровне должен быть создан единый цифровой рынок 
покупателей и продавцов, устраняющий политические, экономические, культурные и др. барьеры, обеспечивающий свободное движение людей, услуг и капитала в виртуальном пространстве и поддерживающий новые модели деятельности и сферы деловой активности [2].Цифровые информационные технологии должны обеспечить для всех уровней управления построение: цифровых платформ - это распределенные инфокоммуникационные системы субъектов единого цифрового рынка, которые имеют открытые интерфейсы для доступа значительного числа других платформ, пользователей и умных вещей к определенному набору услуг. экосистемы цифровой экономики - это форма и среда партнерства организаций, органов власти и граждан, которые обеспечивают постоянное взаимодействие принадлежащих им цифровых платформ для создания инновационных решений, новых технологий, продуктов и услуг. Базовые условия для развития цифровой экономики включают:

- «цифровой кодекс» для снятия юридических ограничений (налоги, права потребителей, авторское право и т.п.) и создания правил использования данных и систем в виртуальной среде;

- образование и науку для развития интеллектуальных ресурсов, подготовки кадров, взаимодействия между бизнесом и учеными и др.;

- гарантии безопасности информационного взаимодействия субъектов.

Программа цифровой экономики РФ в основном посвящена двум нижним уровням, а наши занятия - технологиям цифровой экономики [3].

Создание цифровой экономики должно основываться на архитектурном подходе.

Основные понятия, связанные с архитектурой систем, сформулированы в стандартах ГОСТ Р ИСО/МЭК 15288, ANSI/IEEE 1471, ISO/IEC/IEEE 42010 и др.

Архитектура системы - это комплекс основополагающих принципов организации системы, которые воплощены в наборе ее компонентов, связях компонентов друг с другом и с внешним окружением, а также принципов проектирования и развития системы.

Архитектура может иметь несколько представлений, отражающих интересы различных групп заинтересованных лиц. Рассмотрим архитектуру цифровой экономики с технологической точки зрения.

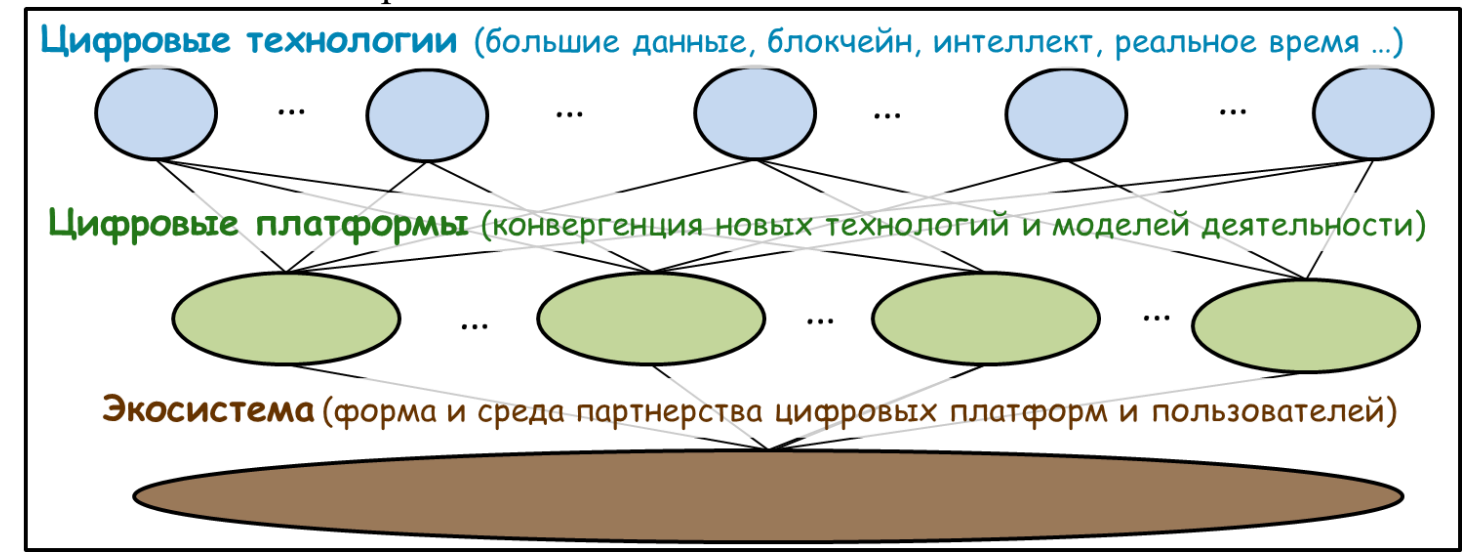

Рисунок 1. - Архитектура циифровой экономики.

По современным представлениям цифровая среда должна быть подобна экологическим системам, созданным природой [4].Природа объединяет все совместно функционирующие организмы на каждом участке Земли и обеспечивает взаимодействие с физической средой таким образом, что поток энергии создает четко определенные биотические структуры и круговорот веществ между живой и неживой частями [5]. Экосистема цифровой экономики объединяет возможности различных цифровых платформ на информационном уровне. Структуры, производящие требуемые товары и услуги, создаются информационными потоками, которые циркулируют между 
платформами и пользователями и получают новые свойства каждый раз при достижении ими тех или иных цифровых платформ.

В основе лежит 3 технологических принципа:

- сетевой,

- открытости технологий,

- открытости данных.

Задача экосистем - организовать информационные потоки и сделать их доступными цифровым платформам и пользователям. Создание цифровых платформ это двуединая задача разработки новых: 1) технологий, «обеспечивающих обработку гигантских объемов данных и поддержку всеохватных информационных систем»; 2) моделей деятельности на базе возможностей этих систем [6].

По назначению цифровые платформы можно разделить на технологические платформы (доступ к тем или иным сквозным технологиям) и бизнес-платформы (предоставляют ту или иную услугу конечным пользователям).Цифровые платформы являются основными строительными блоками для цифровой экономики [7]. Их главные свойства: - открытые защищенные интерфейсы для информационного взаимодействия с внешним окружением;- предоставление виртуальных площадок для коммуникации участников рынка;

- coхранение, распространение и обработка огромных объемов данных;

- предоставление услуг клиентам, распределенным на большой территории;

- облачный характер услуг (XaaS - все как сервис), предоставление услуг в реальном времени по первому требованию с оплатой за реальный объем потребления;

- основные активы - это новые инновационные разработки и бизнес-идеи;

- отход от субъект объектной концепции, интеграция материальной (предметной) и управленческой деятельностей при производстве, распределении, обмене и потреблении блага;

- полная автоматизация практически всех видов деятельности;

- принятие решений в масштабе всего предприятия-платформы и др.

Главное - это организация связей с внешним окружением [8], а не внутреннее устройство. Цифровые платформы являются распределенными информационными системами, управление которыми может быть централизованным или децентрализованным.

Выделим 4 уровня технологий централизованных цифровых платформ. Технологии цифровизации деятельности основаны на интернете вещей, 3D-печати, роботизации и других достижениях, которые объединяют реальную (аналоговую) и виртуальную (цифровую) среды и за счет этого меняют принципы организации деятельности в различных предметных областях, таких как медицина, образование, производство, логистика, финансы, страхование, экология, с/х, строительство и др. В результате трансформируются все традиционные «аналоговые» рынки и возникают условия для создания новых цифровых рынков и бизнес-платформ.

Сквозные информационные технологии обеспечивают непрерывную полностью автоматическую (сквозную) обработку данных в интересах всех или нескольких цифровых платформ и предметных областей: большие данные, искусственный интеллект, виртуальная и дополненная реальность, нейротехнологии, API, APP и др. Операторы сквозных технологий формируют технологические платформы.

Инфокоммуникационные технологии создают распределенную инфраструктуру и единое информационное пространство: мобильный широкополосный доступ, инфокоммуникационные сети, облачные и туманные вычисления, центры обработки данных, суперкомпьютеры и др. Операторы соответствующих систем и сетей формируют рынок инфраструктурных услуг [9]. 
Технологии физической реализации развиваются благодаря фундаментальным научным исследованиям, создающим все новые физические способы представления, распространения и обработки данных: электроника, фотоника, радиотехника, квантовые технологии и др.

Трансконтинентальные корпорации создают новый бизнес, основанный на принципах цифровой экономики. При содействии правительств строятся глобальные цифровые бизнес-платформы и новые модели бизнеса, автоматизирующие обмен ценностями между независимыми группами клиентов.

Еще одним аспектом цифровой экономики является программируемая экономика. Это хозяйственная деятельность, основанная на информационном взаимодействии между компаниями и людьми без централизованных контроля и регуляторов. Основой элемент децентрализованные автономные организации (ДАО).Децентрализованные потому, что права владения и процессы принятия решений выражены в блокчейне, который контролируется большим числом равноправных «акционеров» (сетевых узлов), получающих за это вознаграждение. Автономные потому, что организация работает независимо от человеческого вмешательства, исполняя умные контракты. Может быть задействована система выборов группы анонимных «делегатов», которые за определенную плату токенами (монетами блокчейна) принимают решения, работая независимо друг от друга и не формируя иерархическую структуру.Умный контракт компьютерный алгоритм (приложение блокчейна), исключающий человеческий фактор при проверке условий и инициировании событий в реальном или виртуальном мире. Позволяет обмениваться деньгами, собственностью, акциями, данными или любыми другими активами и объектами без посредников. Написанный на компьютерном, а не юридическом языке, он всегда исполняется без воздействия внешних сил. Экономика, основанная на блокчейне, не зависит от человеческих пороков и коррупции, также как от сочувствия и креативности. Она функционирует в соответствии с открытым программным кодом. Большинство проектов на базе блокчейна находятся или на этапе разработки концепции, или проходят испытания (недвижимость, земельный кадастр, облачное хранение данных, интеллектуальная собственность, жизненный цикл автомобилей и др. собственности, нотариальные услуги, пенсионный фонд, история болезней, счета-фактуры). Главная сложность создания Блокчейн заключается в выборе сценария использования технологии, а не в технической реализации[10].

Для создания цифровой экономики необходимо следовать сложной многоцелевой программе, нацеленной на создание глобального цифрового рынка, развитие информационных технологий и изменение базовых условий экономической деятельности. Технологическую основу цифровой экономики создают цифровые платформы, организованные в экосистему. Цифровые платформы могут иметь централизованное и децентрализованное управление. Бизнес, основанный на централизованных цифровых платформах, уже привел к трансформации мировых рынков, но не обеспечивает безопасного информационного взаимодействия. Особенности децентрализованных цифровых платформ иллюстрирует развитие платформы Биткойн. Их широкое внедрение можно ожидать до 2019 - 2020 гг.

$$
* * *
$$

1. Калужский М.Л. Маркетинговые сети в электронной коммерции: институциональный подход / М.Л. Калужский. - М.; Берлин: Директ-Медиа, 2014. - 402 с.

2. Колбанёв М.О., Коршунов И.Л. Информационно-технологическое обеспечение цифровой экономики. // Информационные технологии цифровой экономики. - 2017. С. 5-9.

3. Проект Программы «Цифровая экономика Российской Федерации». [Электронный ресурс]. Режим доступа: http://d-russia.ru/wp-content/uploads/2017/05/programmaCE.pdf.

4. Воробьев А.И., Колбанёв А.М., Колбанёв М.О. Зеленые информационные технологии. // Ученые записки Международного банковского института. - 2015. № 12. - С. 153-164.

5. Одум Ю. Экология: В 2-х т. - Ecology / Пер. с англ.. — М.: Мир, 1986. — Т. 1. — 328 с.; Т. 2. — 376 с. 
6. Gartner [Электронный pecypc]. Режим доступа: http://www.gartner.com/technology/home.jsp.

7. Воробьев А.И., Татарникова Т.М. Применение генетического алгоритма для решения задачи обеспечения отказоустойчивости вычислительного кластера. // Информационные технологии и системы: управление, экономика, транспорт, право. - 2011. № 1. - С. 3.

8. Советов Б.Я., Воробьев А.И. Применение методов оптимизации в задачах структуризации корпоративного центра обработки данных. // Известия СПбГЭТУ ЛЭТИ. - 2012. № 8. - С. 41-46.

9. Воробьев А.И., Колбанёв А.М., Колбанёв М.О.Экологическая безопасность информационных технологий. // Геополитика и безопасность. - 2015. № 4 (32).- С. 90-99.

$\begin{array}{llll}\text { 10. Gartner [Электронный } & \text { ресурс]. }\end{array}$ https://www.gartner.com/search/site/premiumresearch/simple?tabChg=true\&keywords=programmable economy.

\title{
Стерлева А.С. \\ Анализ необходмости использования инструмента взаимодействия пользователей с информационным отделом
}

\author{
НИУ «БелГУ》 \\ (Россия, Белгород)
}

doi: $10.18411 /$ sr-10-12-2017-04

idsp: 000001:sr-10-12-2017-04

\section{Аннотация}

Автоматизированные системы стали неотъемлемой частью работы современного предприятия. Для улучшения работы сотрудников необходимо внедрять новые инструменты работы. Таким инструментом, позволяющим сделать работу сотрудников компании лучше - является система заявок.

Ключевые слова: Сфера ИТ, современные технологии, ИТ инфраструктура предприятия, программный продукт, система заявок.

Совершенствование, улучшение, модернизация чего-либо на предприятии - это ёмкий и сложный процесс. Предприятия с большой численность работников все время требуют изменений в привычном укладе работы. Особенных изменений на предприятии требует сфера ИТ, из-за постоянных нововведений и совершенствования современных технологий.

Когда на предприятии количество рабочих мест, оборудованных персональным компьютером не перестает увеличиваться, то целесообразно разработать инструмент, который позволит взаимодействовать пользователям с ИТ отделом и внедрить его в ИТ инфраструктуру предприятия. Под инструментом понимается - программный продукт, позволяющий пользователю, у которого возникла проблема на его персональном рабочем месте, обозначить её специалисту с помощью автоматизированной системы подачи заявок.

С точки зрения специалиста и пользователей, внедрение такой системы является эффективным и полезным для использования, так как это заметно упростит задачу специалистам и сократит время обработки поставленной задачи.

На рисунке 1 представлена диаграмма, отображающая отзыв пользователей о форме подачи заявки.

Из диаграммы видно, что подача заявки о возникшей проблеме наиболее удобна через систему заявок. Это связано с рядом преимуществ такой системы:

- значительно экономит время обработки запросов;

- ведение заявок специалистом является простым и легким процессом;

- система сохранят всю историю работы по каждой заявке;

- осуществляется контроль сроков выполнения заявок;

- учет заявок происходит быстрее и эффективнее;

- осуществляется оптимизация рабочего процесса. 